Manuscript prepared for Atmos. Chem. Phys.

with version 1.21 of the $\mathrm{LT}_{\mathrm{E}} \mathrm{X}$ class copernicus.cls.

Date: 29 August 2007

\title{
Electronic Supplement for: The effect of harmonized emissions on aerosol properties in global models - an AeroCom experiment
}

C. Textor ${ }^{1,19}$, M. Schulz ${ }^{1}$, S. Guibert ${ }^{1}$, S. Kinne ${ }^{2}$, Y. Balkanski ${ }^{1}$, S. Bauer ${ }^{3}$, T. Berntsen ${ }^{4}$, T. Berglen ${ }^{4}$, O. Boucher ${ }^{5,18}$, M. Chin ${ }^{16}$, F. Dentener ${ }^{6}$, T. Diehl $^{17}$, J. Feichter ${ }^{2}$, D. Fillmore ${ }^{7,1}$, P. Ginoux ${ }^{9}$, S. Gong ${ }^{10}$, A. Grini ${ }^{4}$, J. Hendricks ${ }^{11}$, L. Horowitz ${ }^{9}$, P. Huang ${ }^{10}$, I. S. A. Isaksen ${ }^{4}$, T. Iversen ${ }^{4}$, S. Kloster ${ }^{2,6}$, D. Koch ${ }^{3}$, A. Kirkevåg ${ }^{4}$, J. E. Kristjansson ${ }^{4}$, M. Krol ${ }^{6,12}$, A. Lauer ${ }^{11}$, J. F. Lamarque ${ }^{7}$, X. Liu ${ }^{13,8}$, V. Montanaro ${ }^{14}$, G. Myhre ${ }^{4}$, J. E. Penner ${ }^{13}$, G. Pitari ${ }^{14}$, M. S. Reddy ${ }^{5,9}$, Ø. Seland ${ }^{4}$, P. Stier ${ }^{2,20}$, T. Takemura ${ }^{15}$, and X. Tie ${ }^{7}$

${ }^{1}$ Laboratoire des Sciences du Climat et de l'Environnement, Gif-sur-Yvette, France

${ }^{2}$ Max-Planck-Institut für Meteorologie, Hamburg, Germany

${ }^{3}$ Columbia University, GISS, New York, USA

${ }^{4}$ University of Oslo, Department of Geosciences, Oslo, Norway

${ }^{5}$ Laboratoire d'Optique Atmosphérique, Université des Sciences et Technologies de Lille, CNRS, Villeneuve d'Ascq, France

${ }^{6}$ European Commision, Joint Research Centre, Institute for Environment and Sustainability, Climate Change Unit, Italy

${ }^{7}$ NCAR, Boulder, Colorado, USA

${ }^{8}$ Battelle, Pacific Northwest National Laboratory, Richland, USA

${ }^{9}$ NOAA, Geophysical Fluid Dynamics Laboratory, Princeton, New Jersey, USA

${ }^{10}$ ARQM Meteorological Service Canda, Toronto, Canada

${ }^{11}$ DLR-Institut für Physik der Atmosphäre, Oberpfaffenhofen, Germany

${ }^{12}$ Institute for Marine and Atmospheric Research Utrecht (IMAU) Utrecht University, The Netherlands

${ }^{13}$ University of Michigan, Ann Arbor, MI, USA

${ }^{14}$ Universita degli Studi L'Aquila, Italy

${ }^{15}$ Kyushu University, Fukuoka, Japan

${ }^{16}$ NASA Goddard Space Flight Center, Greenbelt, MD, USA

${ }^{17}$ Goddard Earth Sciences and Technology Center, University of Maryland Baltimore County, Baltimore, Maryland, USA

${ }^{18}$ Hadley Centre, Met Office, Exeter, United Kingdom

${ }^{19}$ Service d'Aéronomie, CNRS/ UPMC /IPSL, Paris, France

${ }^{20}$ Department of Environmental Science and Engineering, California Institute of Technology, Pasadena, USA

Correspondence to: C. Textor (christiane.textor@1sce.ipsl.fr) 
The models that did not completely follow the requirements for this paper described in Sect. 2 are shaded in gray. This concerns the following models: DLR, KYU, LOA, ARQM, as well as UIO_GCM. 


\section{Figure Captions}

Fig. S1. Emissions [Tg/a] in all models for DU, SS, SO4, BC, POM, and AER (a). For SO4, we show the sum of direct emission and chemical production in ExpA and ExpB. Diversity plots for emissions in ExpA (b) and $\operatorname{ExpB}(\mathrm{c})$. The diversity ranges $( \pm$ Div $= \pm$ standard deviation $)$ are indicated by gray boxes, the diversities are given in gray in the lower part of the plot for each species. The individual models' deviations from the allmodels-averages are plotted as pink lines ('data'), or as pink numbers if they are outside the scale of the plot. The all-models-averages are indicated by a black star (at $0 \%$ ) and the medians by a black line (i.e., deviation of the median from the all-models-average). The numbers of models included in the calculation of this statistics are shown in blue below the $\mathrm{x}$-axis.

Fig. S2. Annual mean emissions averaged over longitudes (left plots) and averaged over latitudes (right plots) in $\left[\mathrm{mg} / \mathrm{m}^{2} / \mathrm{day}\right]$ for SS, DUST, SO4, BC, and POM, respectively, in the models considered for the statistics in ExpA and ExpB. For SO4, we show the sum of direct emission and chemical production in ExpA and ExpB.

Fig. S3. Diversity plots of the sources of sulfur species in a) Experiment A and b) Experiment B. From left to right: $\mathrm{SO}_{2}$ emissions, DMS emissions, sum of presursor ( $\mathrm{SO}_{2}$ and DMS) emissions, sum of precursor loss by deposition, direct SO4 emissions, chemical production of SO4 in the gas and in the aqueous phase, total chemical production, and the sum of all sources. Please note that we only consider the three models that provided both chemical production and precursor gas emissions in both experiments LSCE, UIO_CTM, and ULAQ. The diversities of the individual processes have to be weighted by their relevance for the total SO4 source in order to be compared. For explanations of the plot, please refer to the caption of Fig. S1.

Fig. S4. Global, annual average aerosol mass $[\mathrm{Tg}]$ of the five aerosol species in ExpA and B.

Fig. S5. Column load of total aerosol in $\left[\mu \mathrm{g} / \mathrm{m}^{2}\right]$ (annual averages) in ExpB for the models using the AeroCom emissions. Please note, that we use a non-linear color scale.

Fig. S6. Zonally averaged vertical concentration of total aerosol in $\left[\mu \mathrm{g} / \mathrm{m}^{3}\right]$ (annual averages) in ExpB for the models using the AeroCom emissions. Please note, that we use a non-linear color scale. The white shading of lowest layer above ground in some models indicates that no data have been available in this layer.

Fig. S7. Diversity plots of the annual average aerosol fractions in [\%] of total mass in polar regions in ExpA (a) and $\operatorname{ExpB}($ b). For explanations please refer to the caption of Fig. S1.

Fig. S8. Diversity plots of the global, annual average fractions in [\% ] of total mass above $5 \mathrm{~km}$ altitude for the AeroCom models in ExpA (a) and $\operatorname{ExpB}(\mathrm{b})$. For explanations please refer to the caption of Fig. S1. 
Fig. S9. Global, annual average mass fractions in [\%] in different height levels $(0-1,1-2.5,2.5-5,5-10,>10$ $\mathrm{km}$ ) for the AeroCom models in ExpA and ExpB for for SS, DUST, SO4, BC, and POM, respectively.

Fig. S10. Diversity plots for residence times in $\operatorname{ExpA}(\mathrm{a})$ and $\operatorname{ExpB}$ (b), for explanations of the plot please refer to the caption of Fig. S1.

Fig. S11. Contribution of the individual removal processes to the total sink mass flux (annually and globally averaged) for the AeroCom models for (a) SO4 and (b) SS in [\%].The color code is given in the legend. Wet refers to wet deposition. If possible we show the individual dry sink rate coefficients (Tur: turbulent deposition, and Sed: sedimentation), otherwise the sum of the two processes (Dry=SedTur) is plotted.

Fig. S12. Diversities plots of the contribution of wet removal to the total sink mass flux (annually and globally averaged) for the AeroCom models for a) ExpA and b) ExpB. For explanations please refer to the caption of Fig. S1.

Fig. S13. Mass fraction [\%] in the fine mode (radius $<0.5 \mu \mathrm{m}$ ) for DU, SS, and AER (a). Diversity plot for size fractions in $\operatorname{ExpA}(\mathrm{b})$ and $\operatorname{ExpB}(\mathrm{c})$, for explanations please refer to the caption of Fig. S1.

Fig. S14. Effective sink rate coeffcients (annually and globally averaged) for the AeroCom models and for the aerosol species under consideration. The color code is given in the legend: Kwet refers to the wet deposition rate. If possible we show the individual dry sink rate coefficients (Ktur: turbulent deposition, and Ksed: sedimentation), otherwise the sum of the two processes (KSedTur) is plotted. Please note that the ordinates have different scales.

Fig. S15. Diversities plots of the globally and annually averaged effective sink rate coefficients for wet deposition (upper row) and dry deposition (lower row). Left plots: exp A, right plots: exp B. For explanations please refer to the caption of Fig. S1.

Fig. S16. Mass fractions of global annual convective in relation to total wet deposition (convective + stratiform) (a). Diversity plots for mass fractions of global annual convective in relation to total wet deposition in ExpA (b) and B (c). For explanations please refer to the caption of Fig. S1.

Fig. S17. Annual mean aerosol optical depth at 550nm in the AeroCom models for the species under consideration in ExpA and ExpB (a). Diversity plots for aerosol optical depth in ExpA (b) and ExpB (c), for explanations of the plot please refer to the caption of Fig. S1. 


\section{Figures}

a)

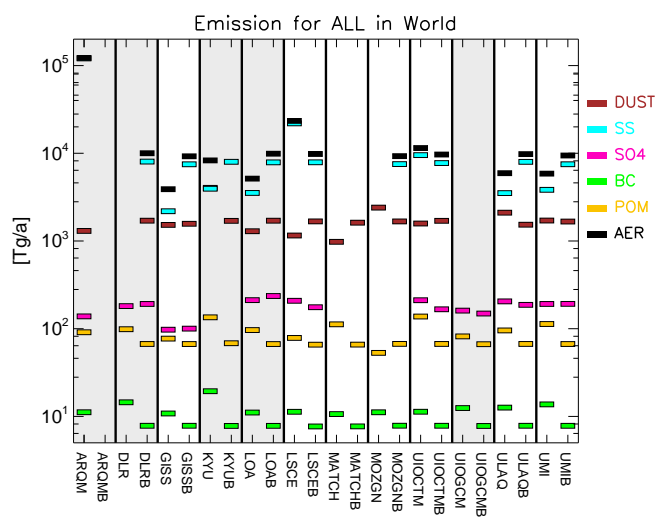

b)

c)
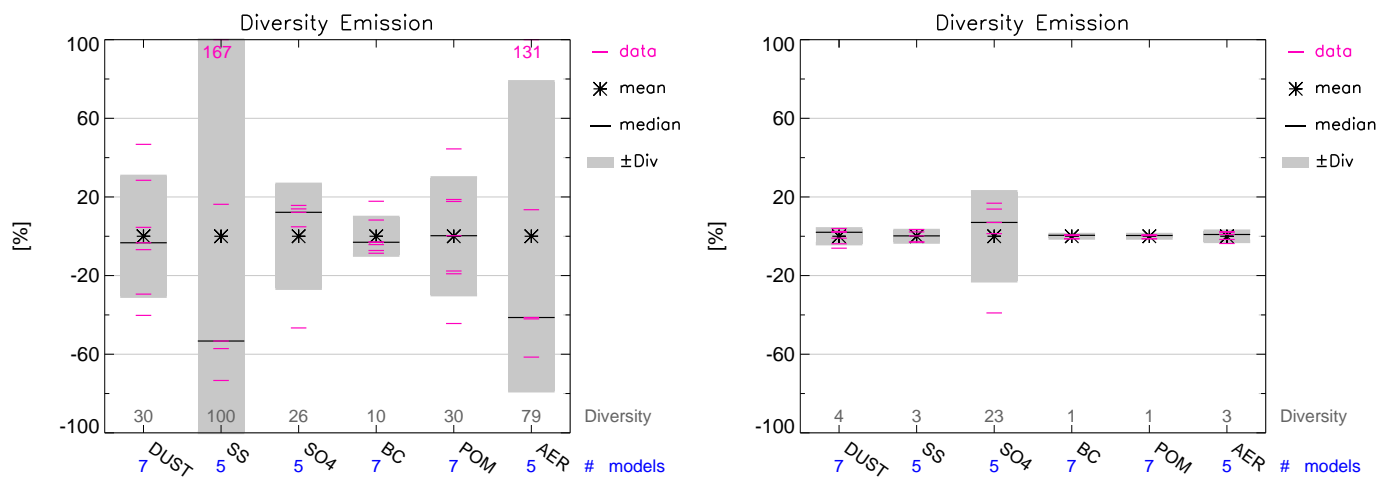

Fig. S1. Emissions [Tg/a] in all models for DU, SS, SO4, BC, POM, and AER (a). For SO4, we show the sum of direct emission and chemical production in ExpA and ExpB. Diversity plots for emissions in ExpA (b) and $\operatorname{ExpB}(\mathrm{c})$. The diversity ranges ( \pm Div $= \pm$ standard deviation $)$ are indicated by gray boxes, the diversities are given in gray in the lower part of the plot for each species. The individual models' deviations from the allmodels-averages are plotted as pink lines ('data'), or as pink numbers if they are outside the scale of the plot. The all-models-averages are indicated by a black star (at $0 \%$ ) and the medians by a black line (i.e., deviation of the median from the all-models-average). The numbers of models included in the calculation of this statistics are shown in blue below the $\mathrm{x}$-axis. 
a)

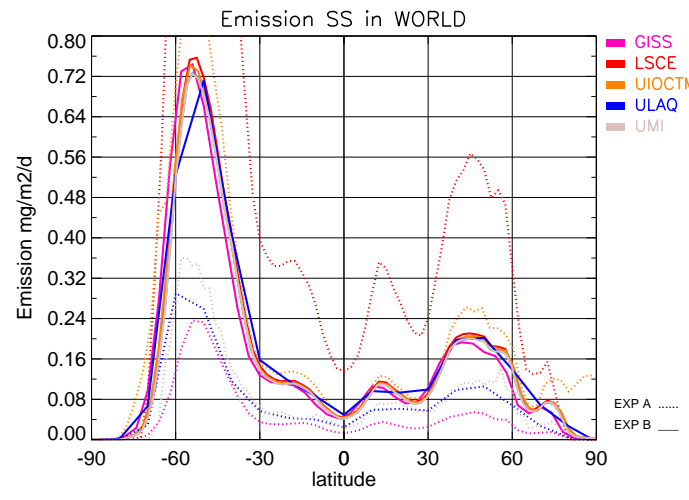

c)

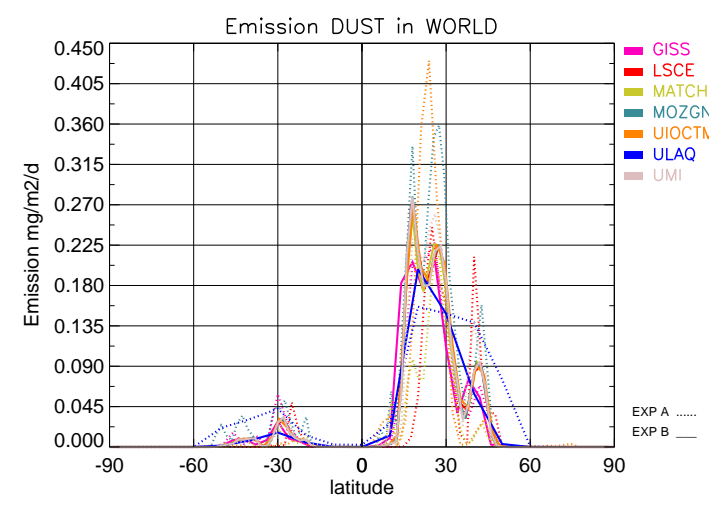

e)

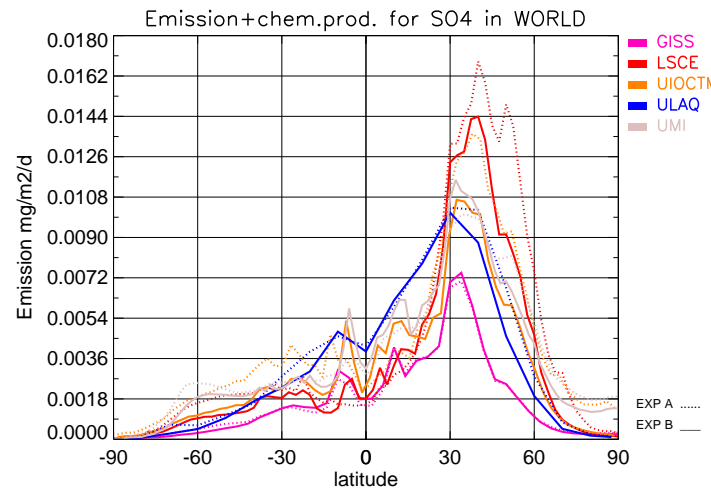

b)

d)

f)
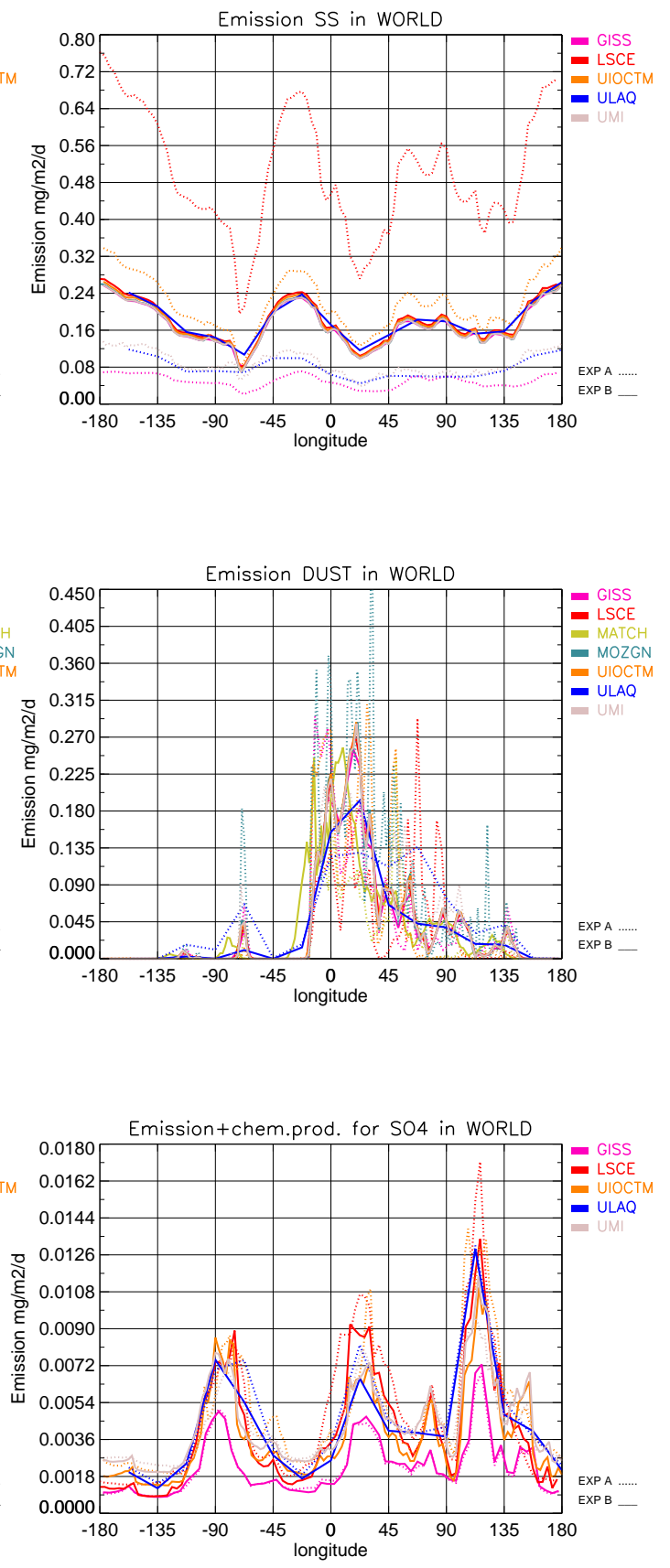
g)

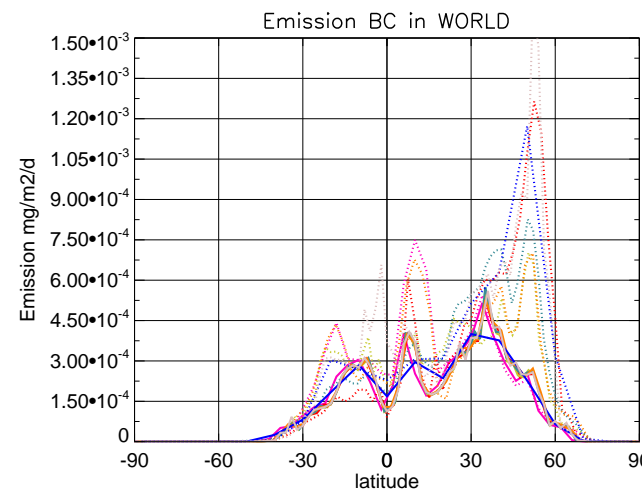

i)

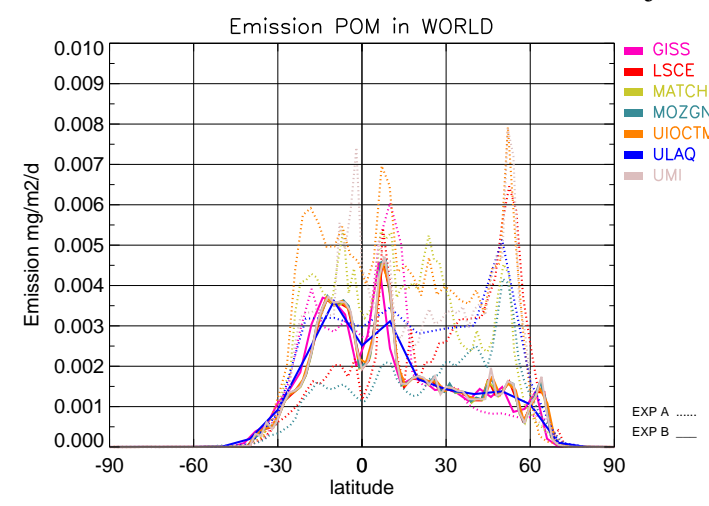

h)

j)
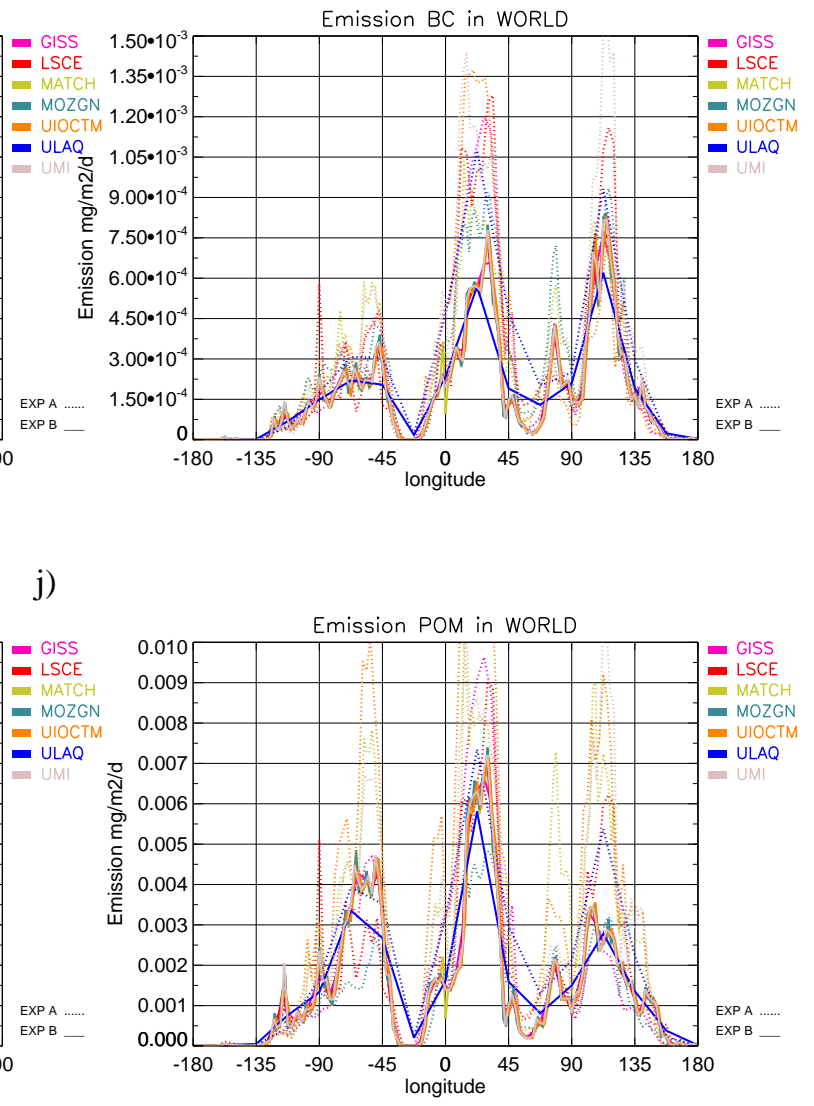

Fig. S2. Annual mean emissions averaged over longitudes (left plots) and averaged over latitudes (right plots) in $\left[\mathrm{mg} / \mathrm{m}^{2} /\right.$ day $]$ for SS, DUST, SO4, BC, and POM, respectively, in the models considered for the statistics in ExpA and ExpB. For SO4, we show the sum of direct emission and chemical production in ExpA and ExpB. 
a)

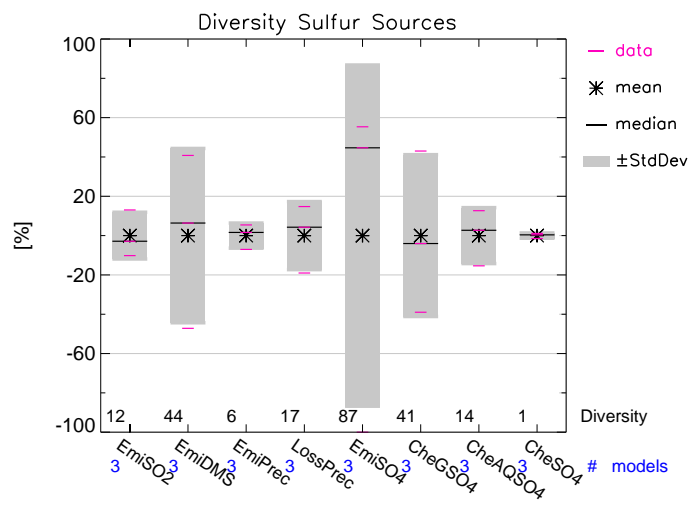

b)

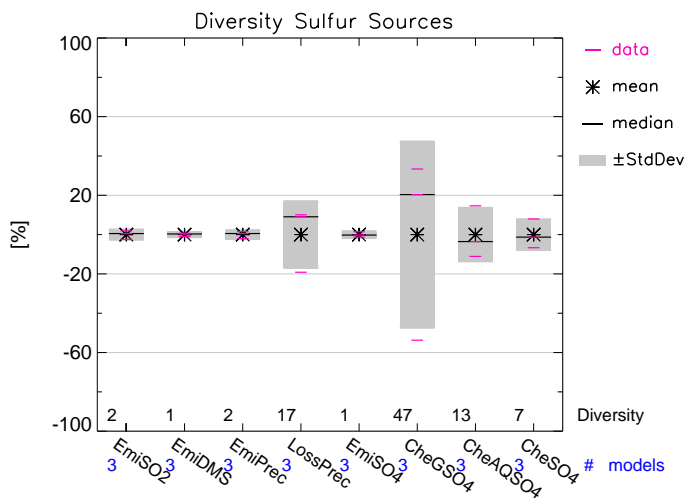

Fig. S3. Diversity plots of the sources of sulfur species in a) Experiment A and b) Experiment B. From left to right: $\mathrm{SO}_{2}$ emissions, DMS emissions, sum of presursor $\left(\mathrm{SO}_{2}\right.$ and $\left.\mathrm{DMS}\right)$ emissions, sum of precursor loss by deposition, direct SO4 emissions, chemical production of SO4 in the gas and in the aqueous phase, total chemical production, and the sum of all sources. Please note that we only consider the three models that provided both chemical production and precursor gas emissions in both experiments LSCE, UIO_CTM, and ULAQ. The diversities of the individual processes have to be weighted by their relevance for the total SO4 source in order to be compared. For explanations of the plot, please refer to the caption of Fig. S1.

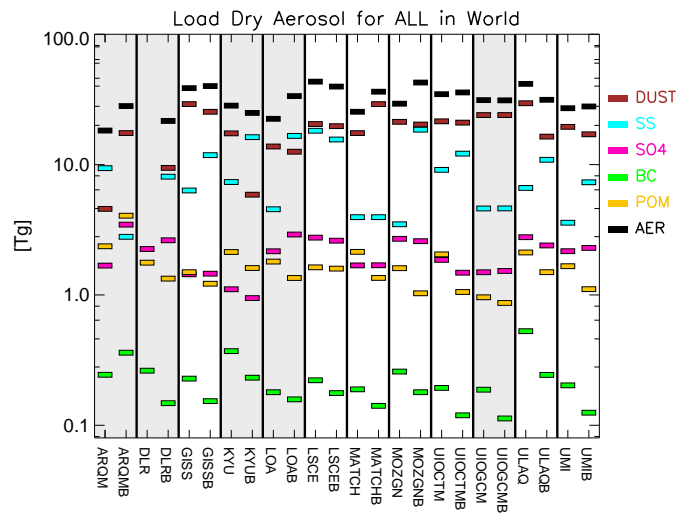

Fig. S4. Global, annual average aerosol mass $[\mathrm{Tg}]$ of the five aerosol species in ExpA and B. 
a)

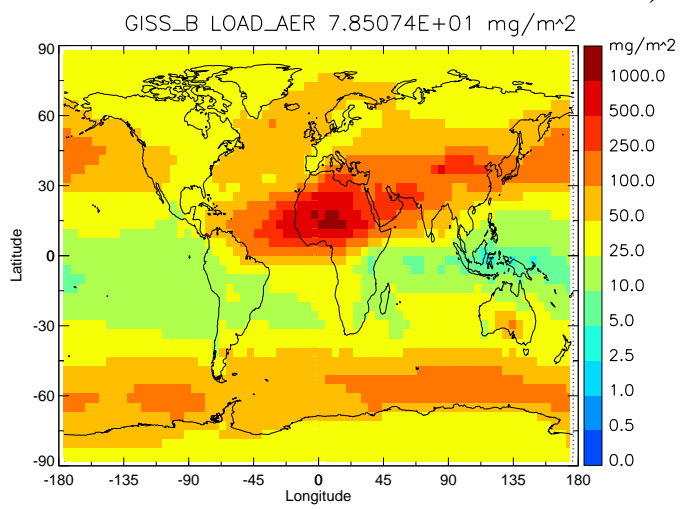

c)

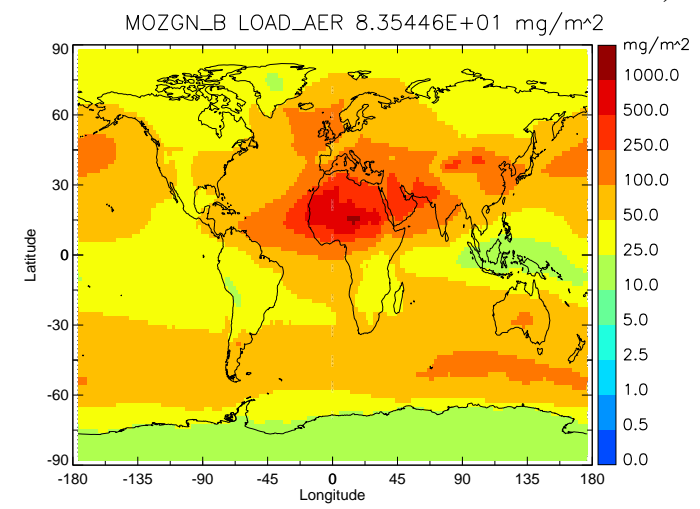

e)

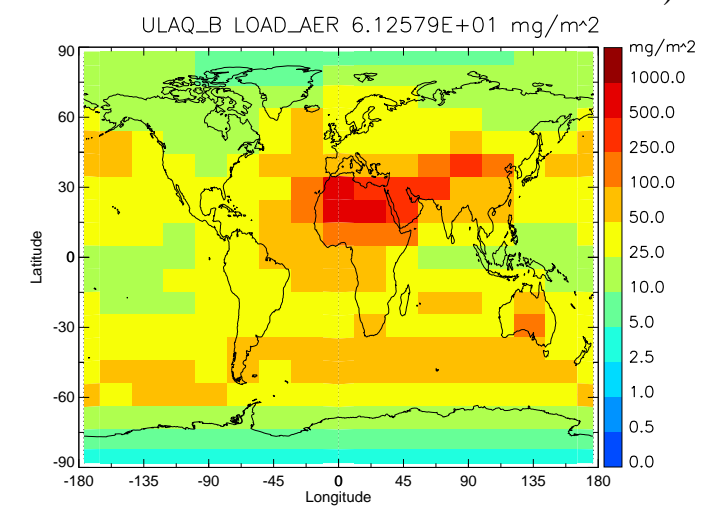

b)

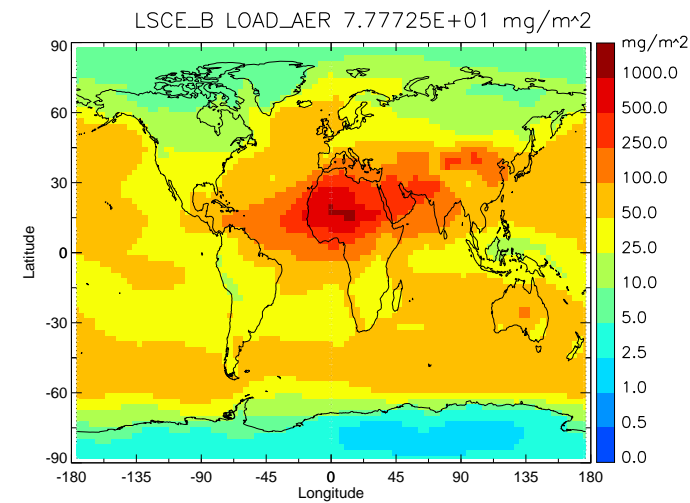

d)

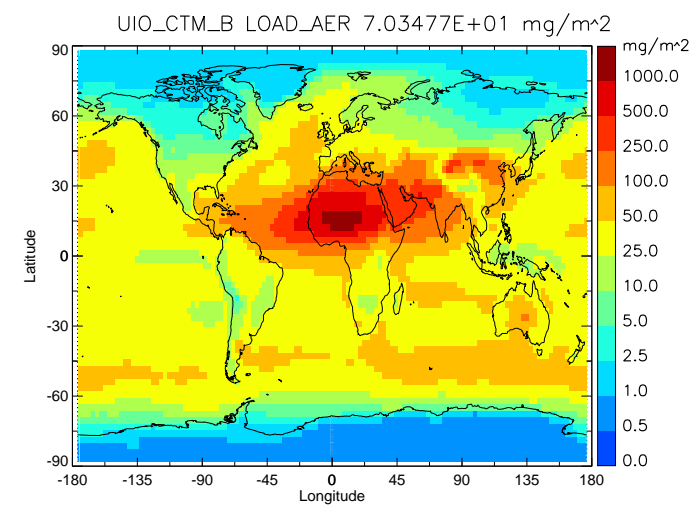

f)

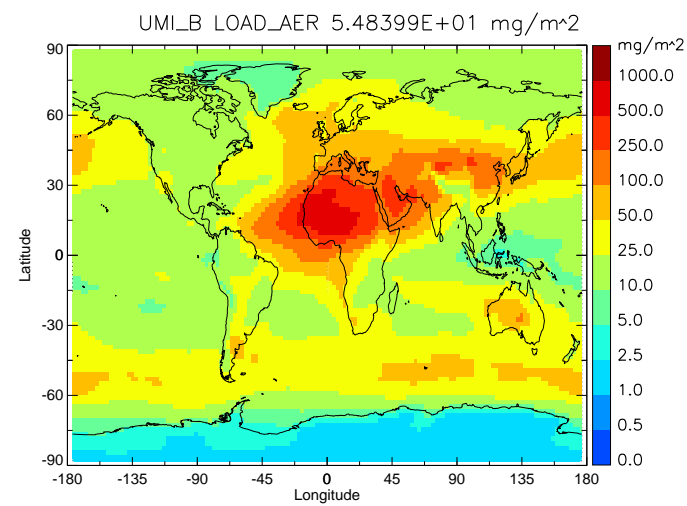

Fig. S5. Column load of total aerosol in $\left[\mu \mathrm{g} / \mathrm{m}^{2}\right]$ (annual averages) in ExpB for the models using the AeroCom emissions. Please note, that we use a non-linear color scale. 
a)

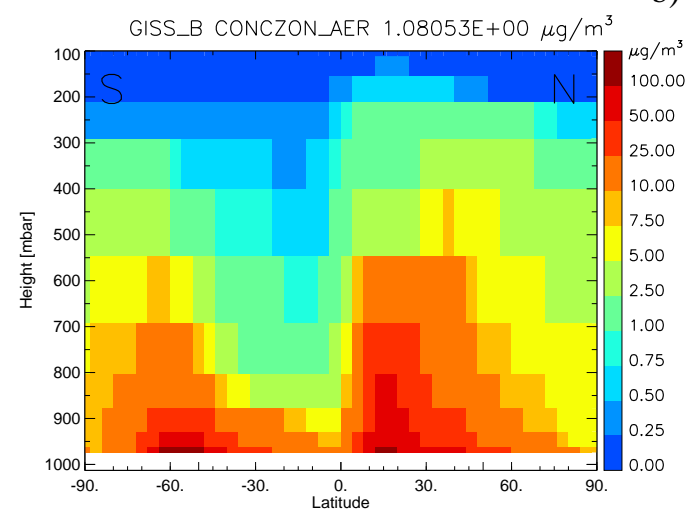

c)

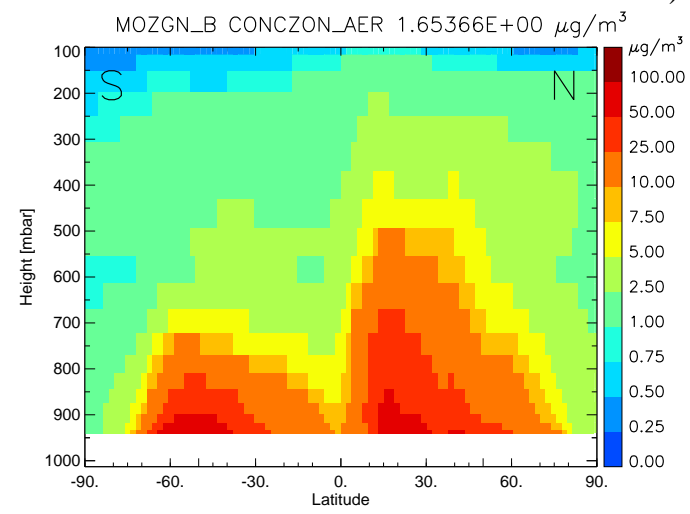

e)

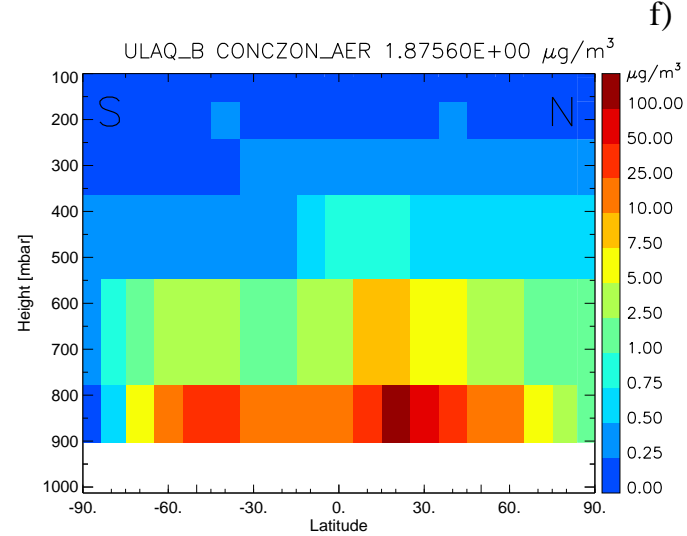

b)

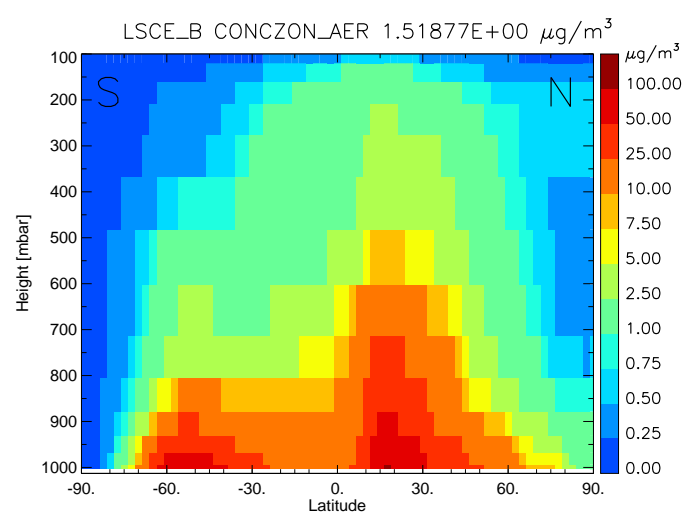

d)

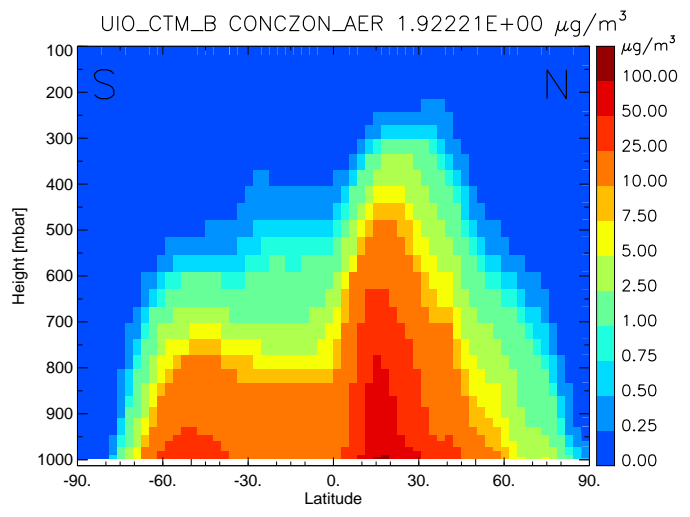

)

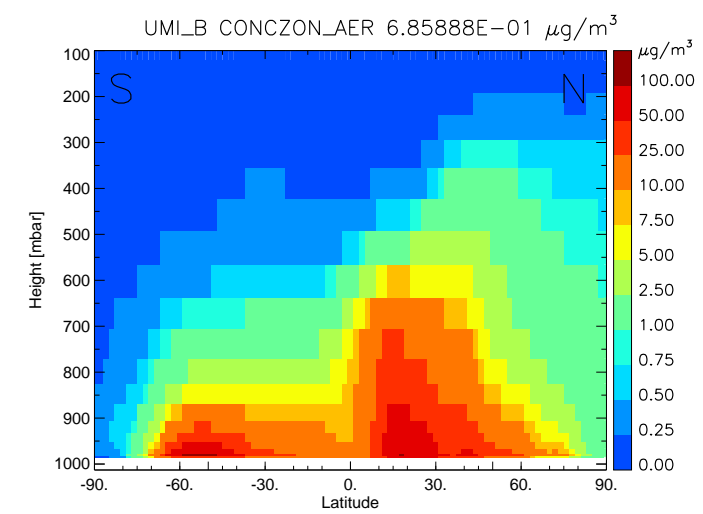

Fig. S6. Zonally averaged vertical concentration of total aerosol in $\left[\mu \mathrm{g} / \mathrm{m}^{3}\right]$ (annual averages) in ExpB for the models using the AeroCom emissions. Please note, that we use a non-linear color scale. The white shading of lowest layer above ground in some models indicates that no data have been available in this layer. 
a)

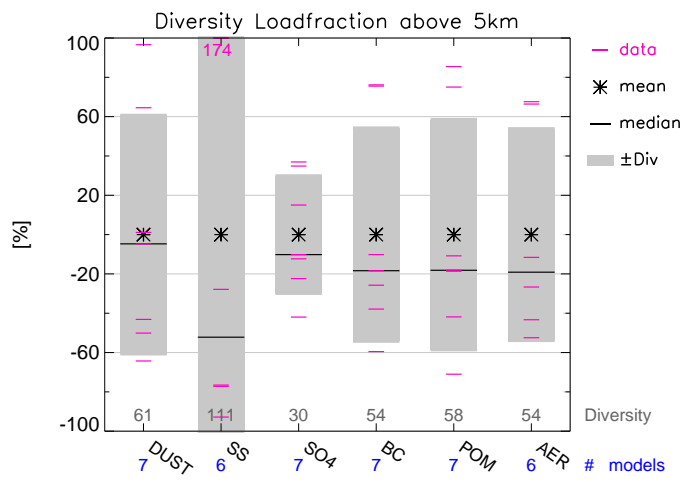

b)

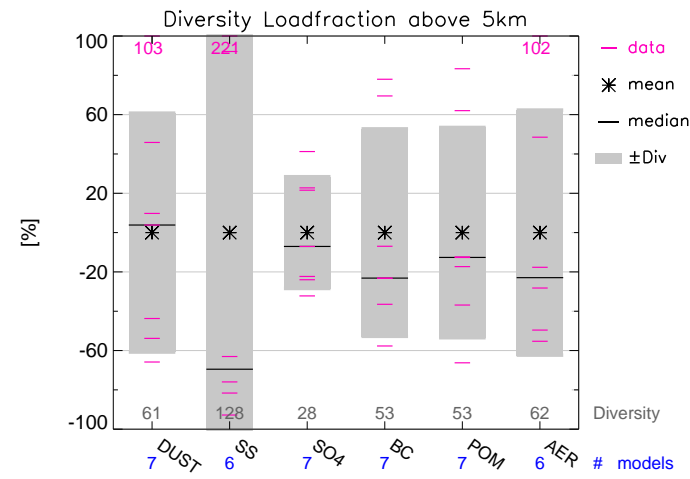

Fig. S7. Diversity plots of the annual average aerosol fractions in [\% ] of total mass in polar regions in ExpA (a) and $\operatorname{ExpB}($ b). For explanations please refer to the caption of Fig. S1.

a)

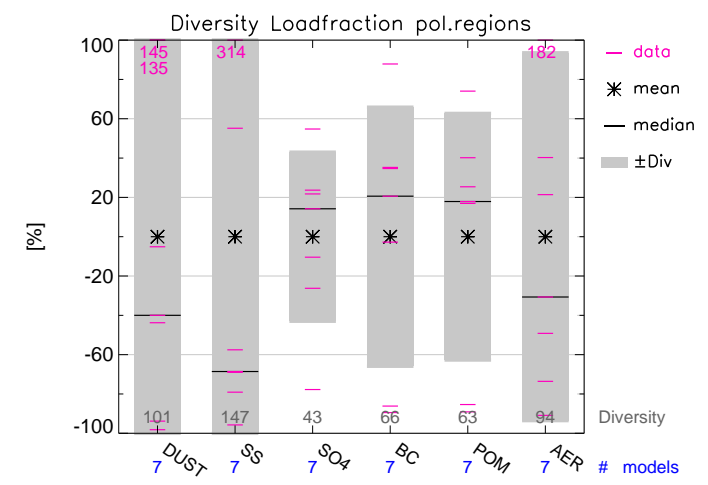

b)

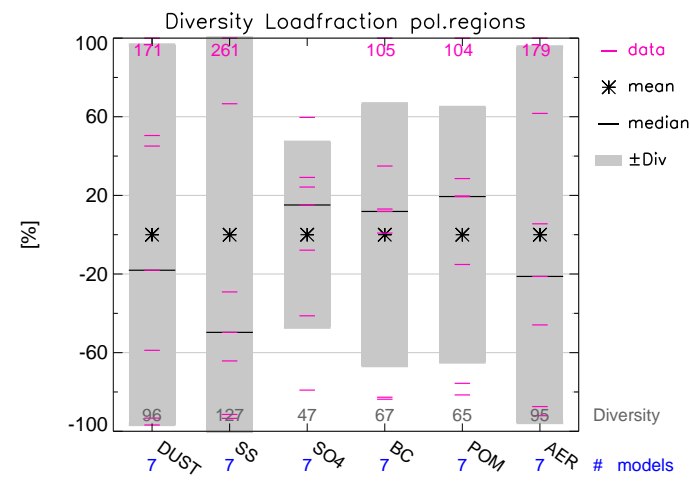

Fig. S8. Diversity plots of the global, annual average fractions in [\% ] of total mass above $5 \mathrm{~km}$ altitude for the AeroCom models in ExpA (a) and ExpB (b). For explanations please refer to the caption of Fig. S1. 
a)

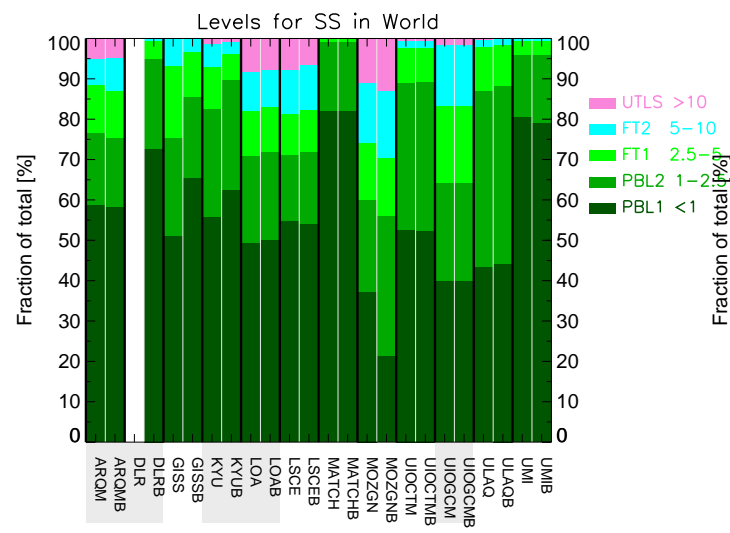

c)

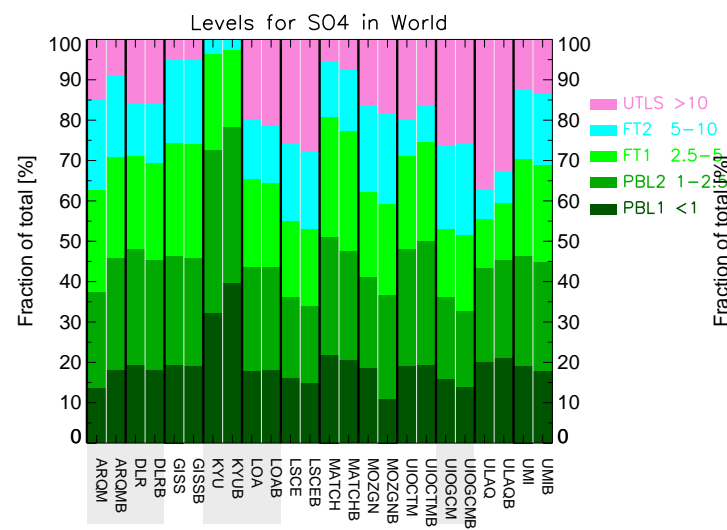

e)

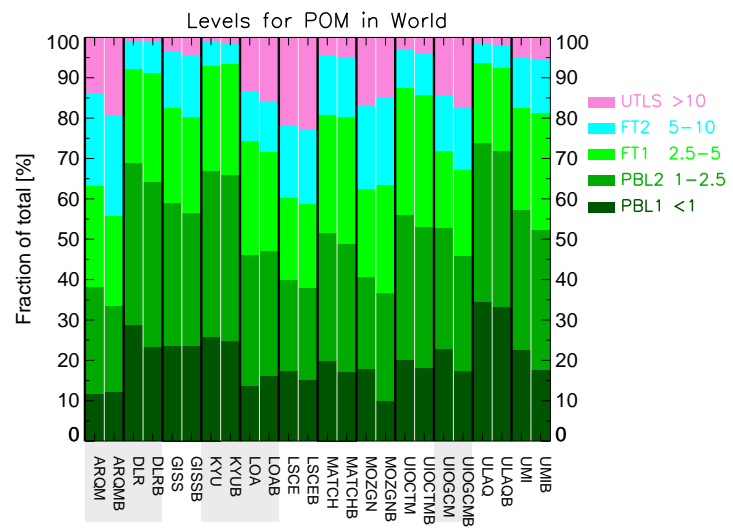

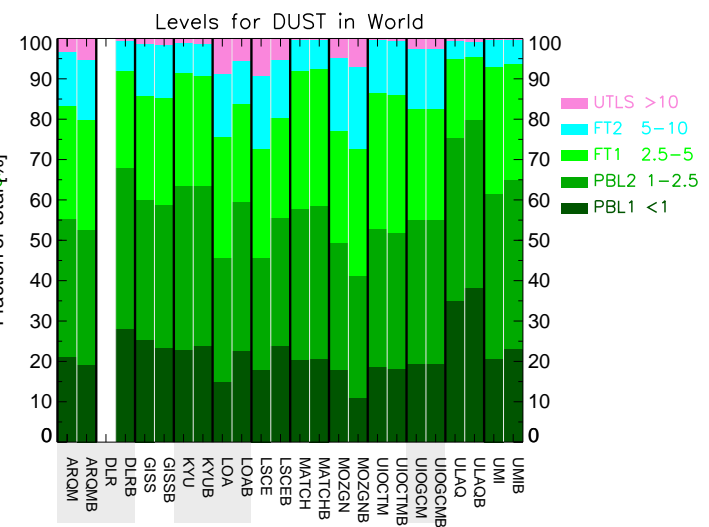

d)

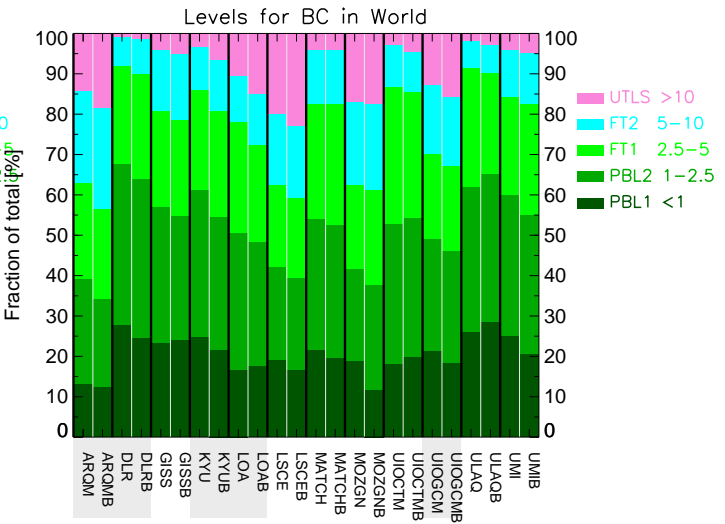

Fig. S9. Global, annual average mass fractions in [\%] in different height levels $(0-1,1-2.5,2.5-5,5-10,>10$ $\mathrm{km}$ ) for the AeroCom models in ExpA and ExpB for for SS, DUST, SO4, BC, and POM, respectively. 
a)

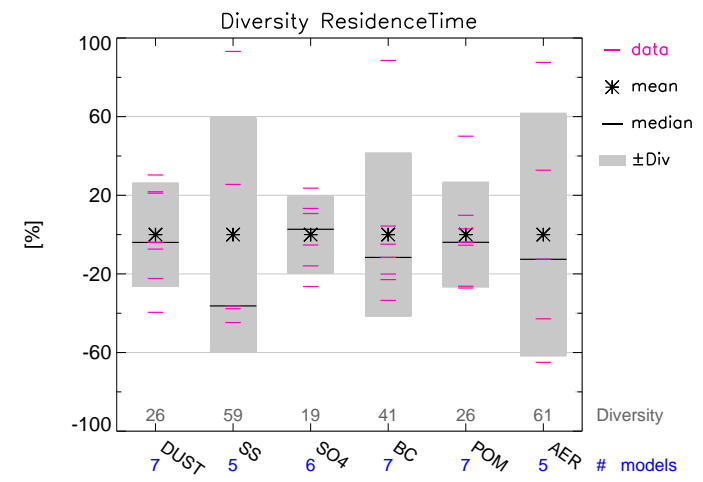

b)

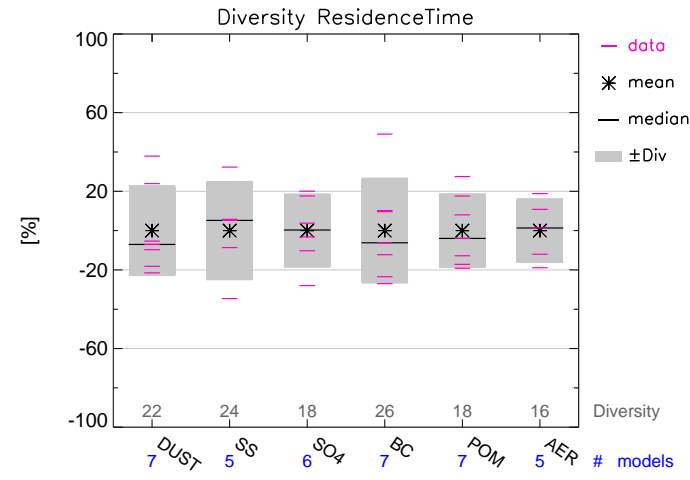

Fig. S10. Diversity plots for residence times in $\operatorname{ExpA}(\mathrm{a})$ and $\operatorname{ExpB}(\mathrm{b})$, for explanations of the plot please refer to the caption of Fig. S1. 
a)

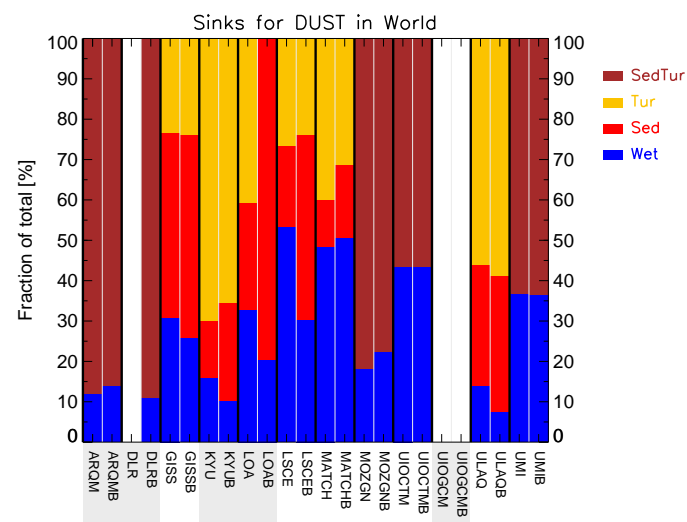

c)

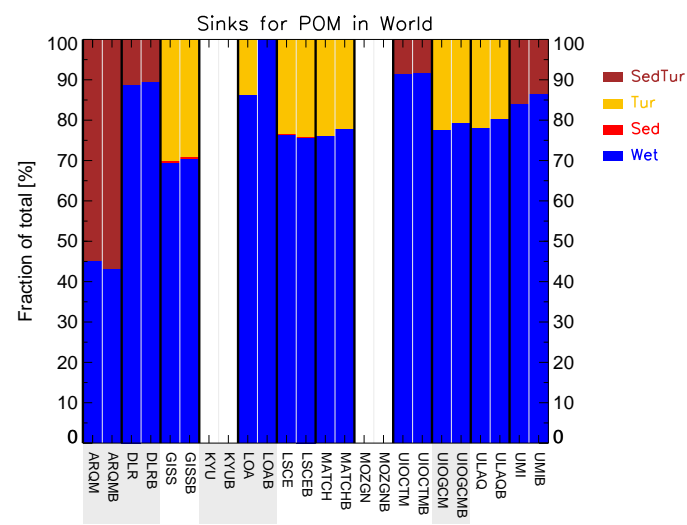

b)

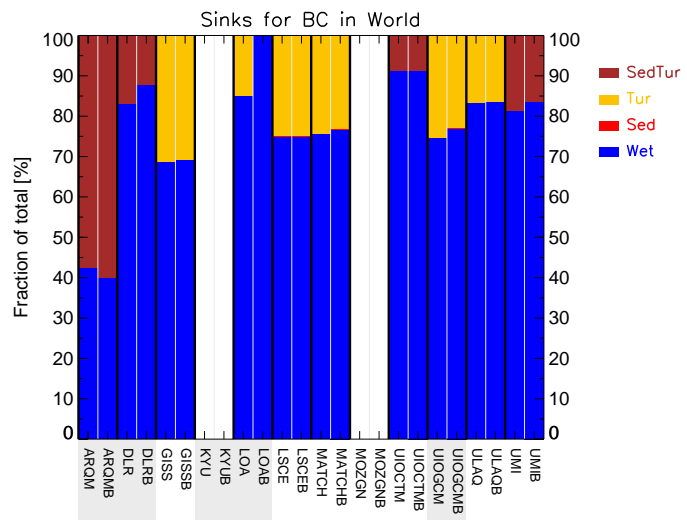

Fig. S11. Contribution of the individual removal processes to the total sink mass flux (annually and globally averaged) for the AeroCom models for (a) SO4 and (b) SS in [\%]. The color code is given in the legend. Wet refers to wet deposition. If possible we show the individual dry sink rate coefficients (Tur: turbulent deposition, and Sed: sedimentation), otherwise the sum of the two processes (Dry=SedTur) is plotted. 
a)

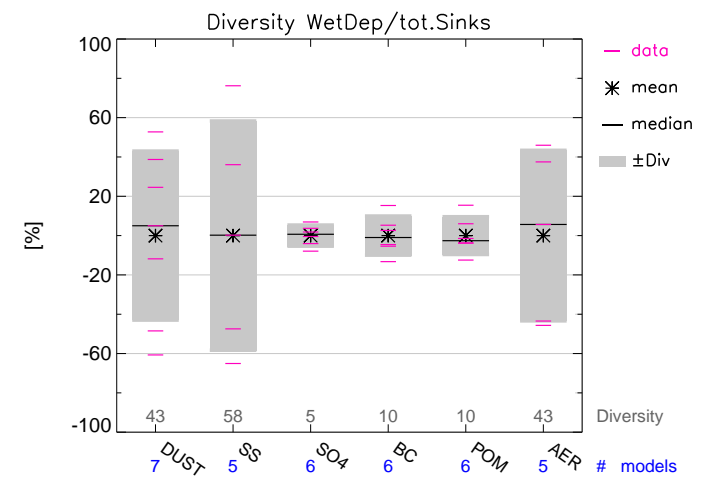

b)

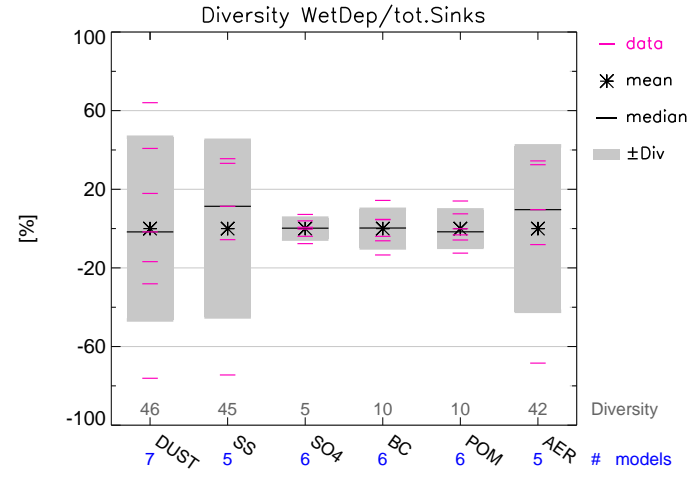

Fig. S12. Diversities plots of the contribution of wet removal to the total sink mass flux (annually and globally averaged) for the AeroCom models for a) ExpA and b) ExpB. For explanations please refer to the caption of Fig. S1. 
a)

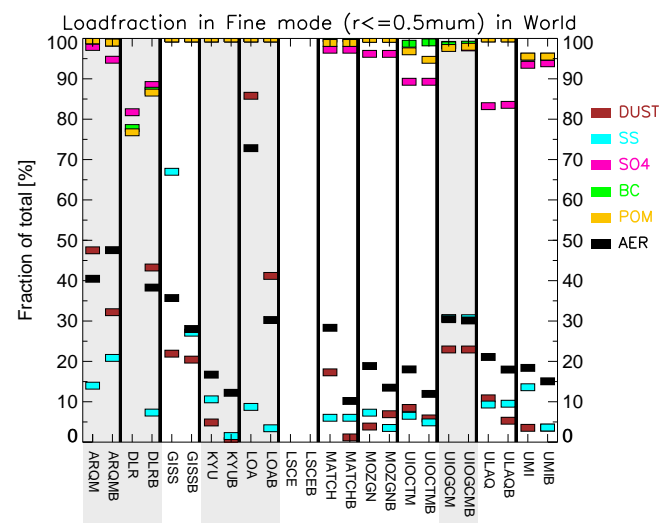

b)

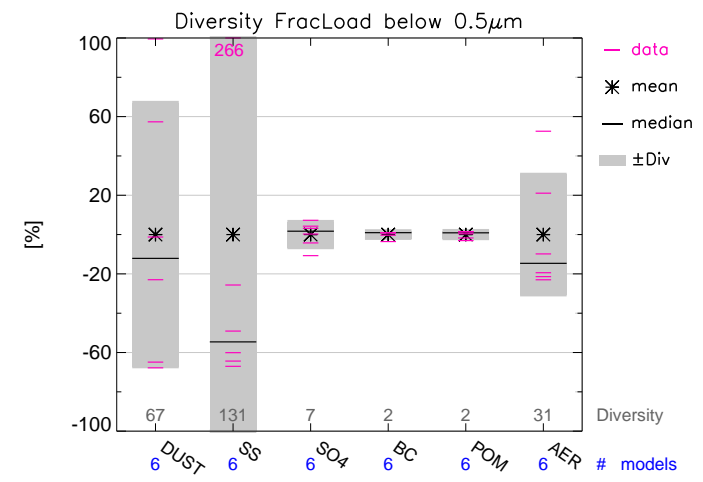

c)

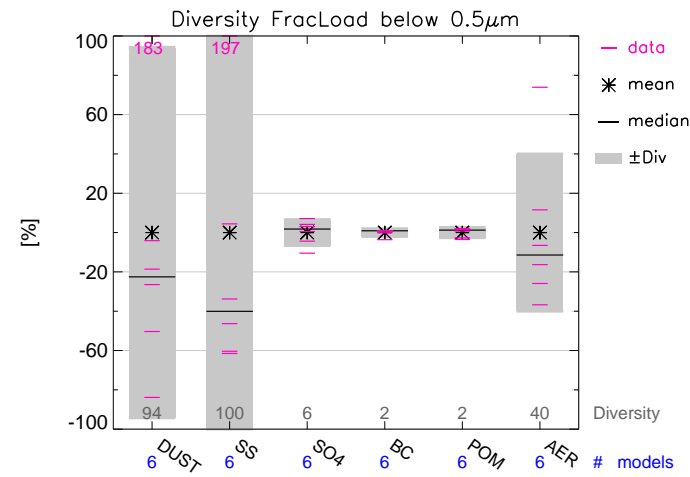

Fig. S13. Mass fraction [\%] in the fine mode (radius $<0.5 \mu \mathrm{m}$ ) for DU, SS, and AER (a). Diversity plot for size fractions in $\operatorname{ExpA}(\mathrm{b})$ and $\operatorname{ExpB}(\mathrm{c})$, for explanations please refer to the caption of Fig. S1. 
a)

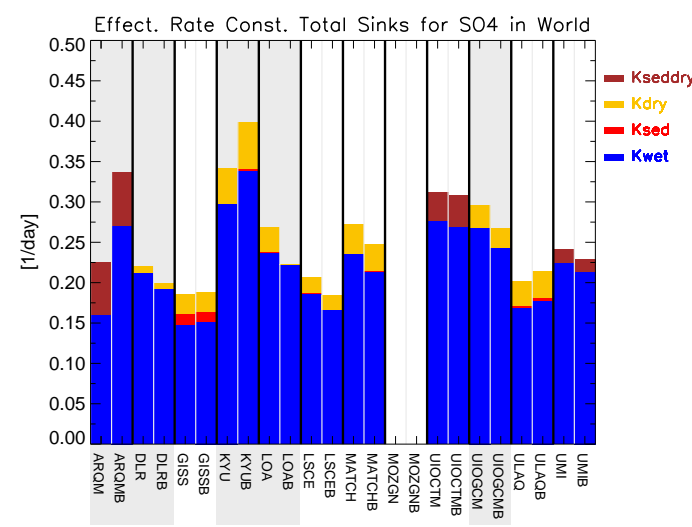

b)

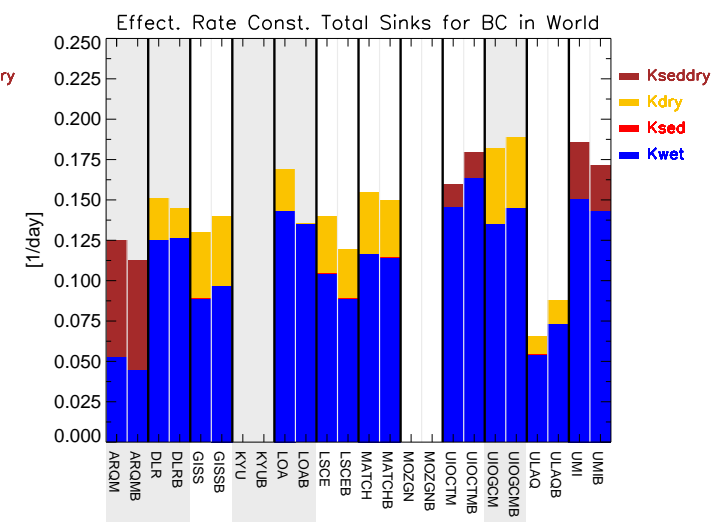

c)
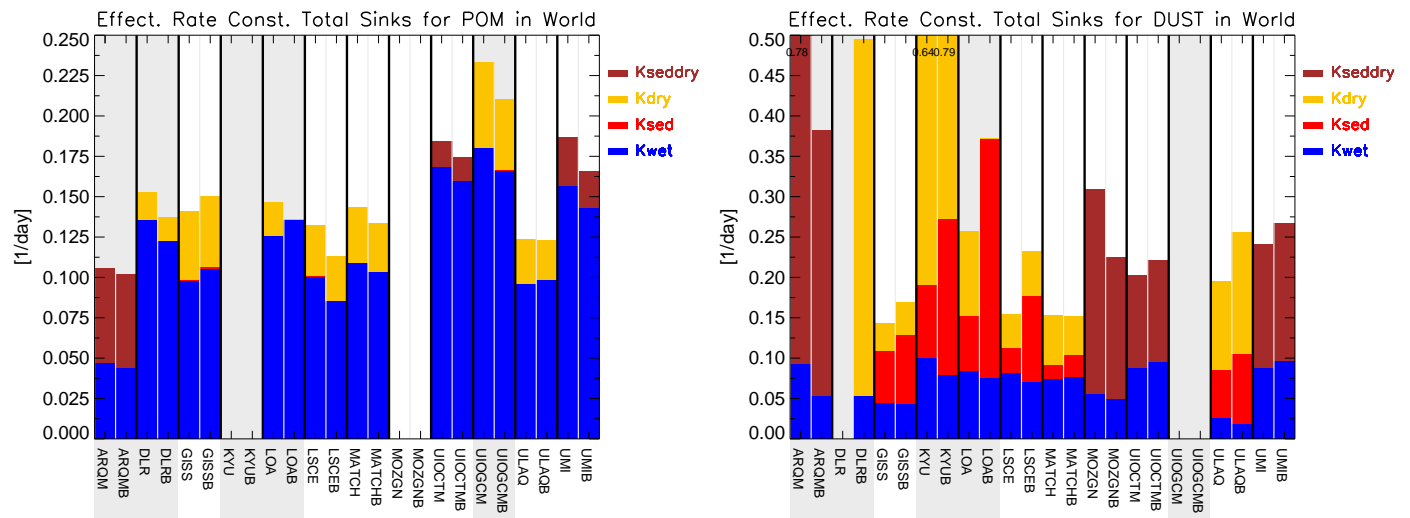

e)

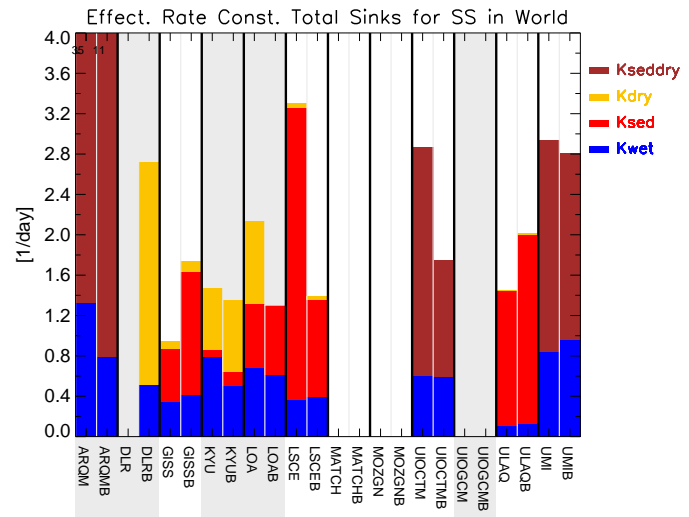

Fig. S14. Effective sink rate coeffcients (annually and globally averaged) for the AeroCom models and for the aerosol species under consideration. The color code is given in the legend: Kwet refers to the wet deposition rate. If possible we show the individual dry sink rate coefficients (Ktur: turbulent deposition, and Ksed: sedimentation), otherwise the sum of the two processes (KSedTur) is plotted. Please note that the ordinates have different scales. 
a)

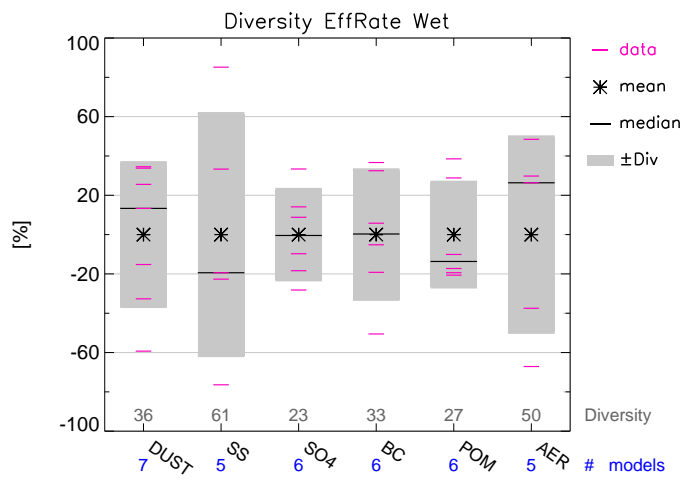

c)

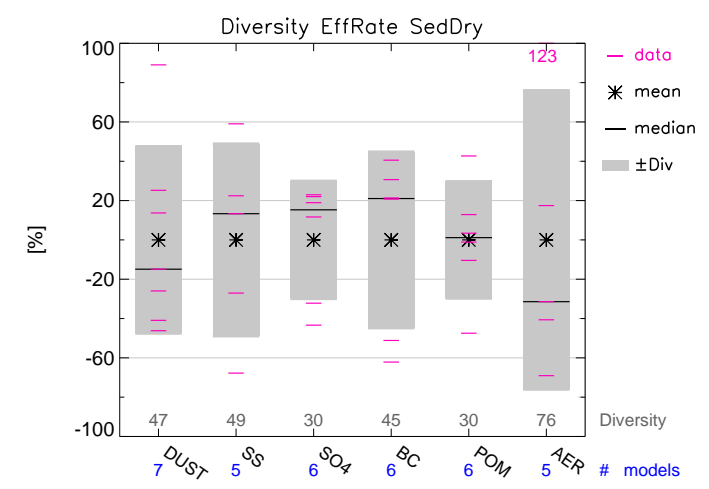

b)

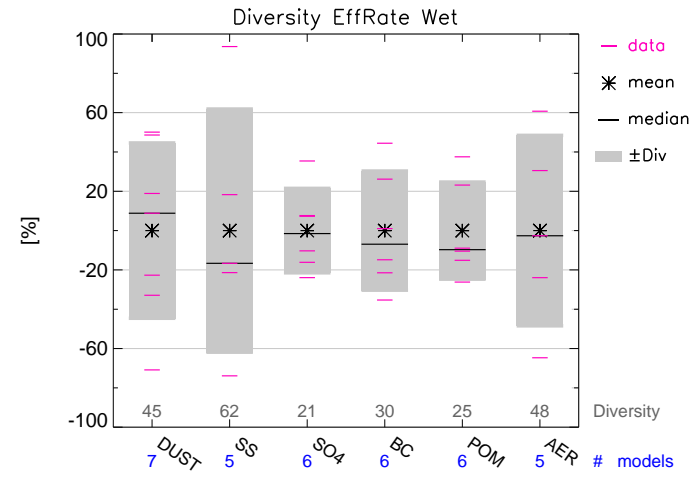

)

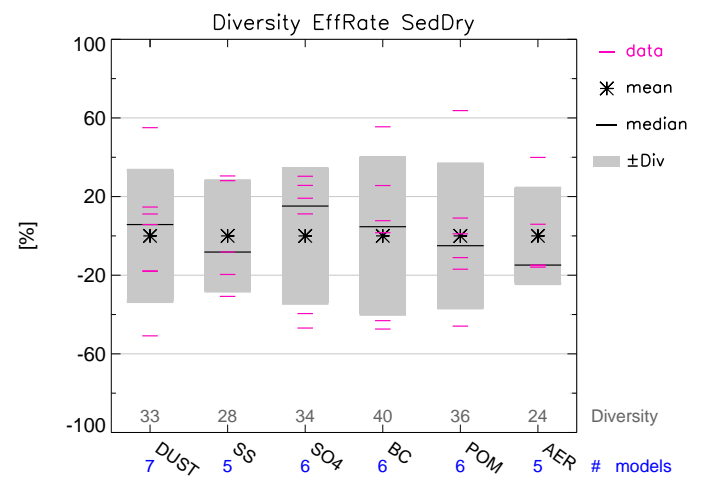

Fig. S15. Diversities plots of the globally and annually averaged effective sink rate coefficients for wet deposition (upper row) and dry deposition (lower row). Left plots: exp A, right plots: exp B. For explanations please refer to the caption of Fig. S1. 
a)

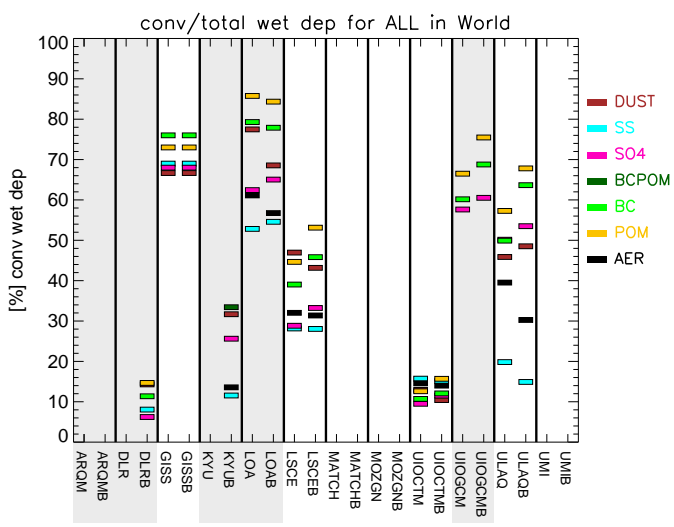

b)

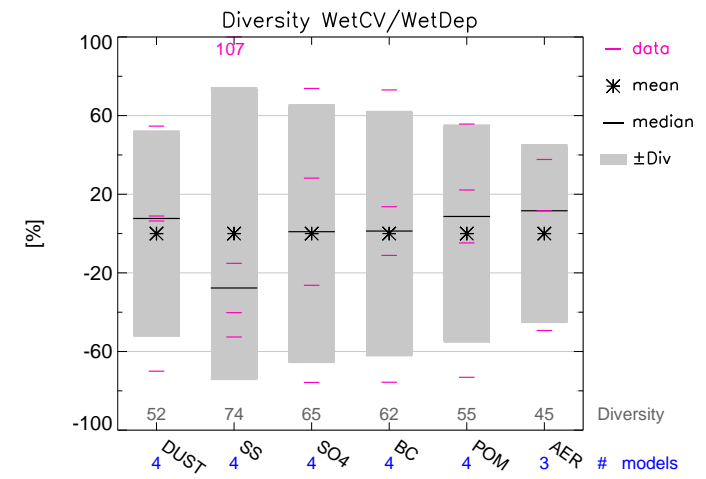

c)

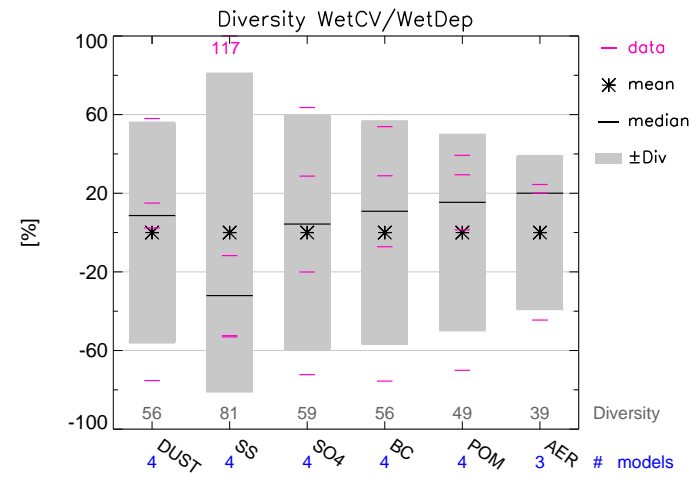

Fig. S16. Mass fractions of global annual convective in relation to total wet deposition (convective + stratiform) (a). Diversity plots for mass fractions of global annual convective in relation to total wet deposition in ExpA (b) and B (c). For explanations please refer to the caption of Fig. S1. 
a)

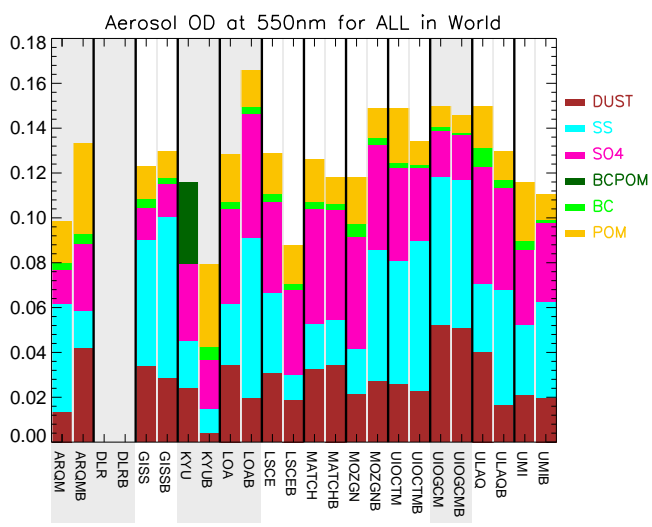

b)

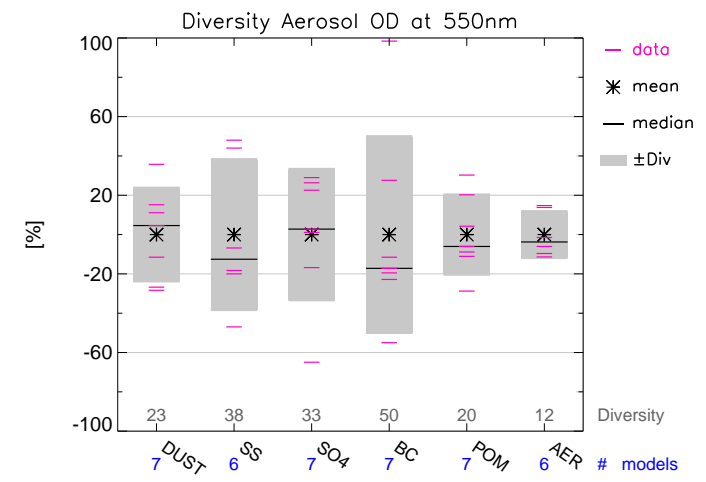

c)

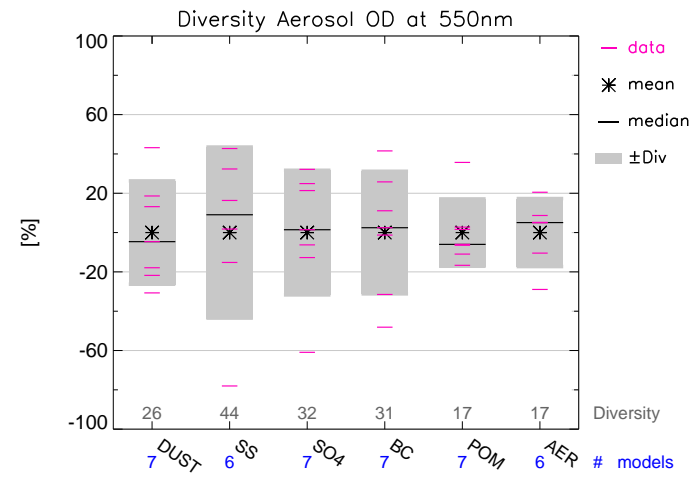

Fig. S17. Annual mean aerosol optical depth at 550nm in the AeroCom models for the species under consideration in ExpA and ExpB (a). Diversity plots for aerosol optical depth in ExpA (b) and ExpB (c), for explanations of the plot please refer to the caption of Fig. S1. 